\title{
Generalized Mathematical Expressions for Various Repayment Plans and Long Term Cost Comparison
}

\author{
Gourav Kumar Vani*, P.K. Awasthi and R.M. Sahu \\ Department of Agricultural Economics and Farm Management, JNKVV, Jabalpur-482004, India \\ *Corresponding author: kumaragri.vani1@gmail.com
}

\begin{abstract}
The financial systems of the day demand greater speed and accuracy which has been provided by digitalization delivered though computers. However, iterative programmes are no better than generalized formulae in saving time and money. This necessitates efforts in finding generalized mathematical formulae. This paper attempts to derive mathematical expression for various repayment plans in general. The generalized expressions derived have been further made use in comparing the cost effectiveness of repayment plans in long run. The straight end repayment plan remains the costliest plan with partial repayment plan being less costly regardless of interest rate and repayment term involved. The cost effectiveness of other plans depends on rate of interest and term of repayment.
\end{abstract}

Keywords: Repayment plans, Amortization, Instalment, Mortgage plans

A well developed financial system is vital to development of a country and its prosperity (Duisenberg, 2001; Mayer, 1990). This becomes more important given the long gestation periods for projects and consequent varying size of cash flows needs appropriate repayment schedules to avoid debt default crisis. This creates need to have special treatment being meted out to borrowers with varying needs. The traditional mortgage plans (alternatively referred to as repayment plans) used by banks have been illustrated by Reddy et al. (2004) in detail. Though these repayment plans are easy to work out manually but given the large chunk of work in banking system and rapidly growing baking system, increasingly more work is being done with the help of computers in banking sector. If various types of repayment plans are to be implemented in computer programmes then generalized mathematical expressions can save a great deal of time and money over iterative programmes in creating proper software interface for this task. It would be a value addition to the work of Reddy et al. (2004) that generalized mathematical formulations simplifies the future task of banker as well as academicians in studying the repayment plans. This paper is devoted to deriving the generalized mathematical expressions for various types of repayment plans. The said output will be used in comparing the repayment plans. The plan of the paper is as following: in next section methodology is discussed followed by section wherein all the repayment plans along with generalized mathematical expressions are discussed and the ensuing section compares the various repayment plans for cost effective in long run with final section concluding the paper.

\section{Data base and Methodology}

The current study extensively used technique of finding sum of geometric progression series. If $a$ is the first term in the series and the ratio by which successive terms are arrived at is $r$ then series can be written as (up to $n^{\text {th }}$ term):

$$
a, a r, a r^{2}, a r^{3}, \ldots, a r^{(n-1)}
$$

Then sum of the $\mathrm{n}$ terms in geometric progression is given by,

$$
S=\sum a r=\frac{a(r)}{r} \text { for } r \neq 1
$$


Where $i^{\text {th }}$ term of the series is defined as $a_{i}=a r^{(i-1)}$ (Wikipedia contributors, 2018).

The other mathematical tool used here is technique of limits and differentiation. Further mathematical induction has been used to prove that the mathematical formulation of the repayment plans is true for any practical value of parameters involved.

\section{RESULTS AND DISCUSSION}

The result and discussion chapter is divided into two parts, A and B. The section A deals with generalized mathematical formulations of various repayment plans while section B focuses on cost comparisons and convergence between various repayment plans.

\section{(A) Generalized Formulations of Various Repayment Plans}

\section{Straight-End payment plan or Single Repayment Plan or Lump sum Repayment plan}

In this repayment plan, farmer pays the interest on principal every year but no part of principal is paid until the loan reaches maturity. At the expiry of the loan period, farmer repays the entire principal amount at once along with interest upon that principal for the last year. Let's assume that a farmer borrows a loan amount $L$ at the rate of $r$ percent per annum for years.

Table 1: Loan Repayment schedule under StraightEnd Repayment Plan

\begin{tabular}{ccccc}
\hline Year & Principal & Interest & Instalment & Balance \\
\hline 1 & 0 & L.r & L.r & $L$ \\
2 & 0 & L.r & L.r & $L$ \\
3 & 0 & L.r & L.r & $L$ \\
$\ldots$ & $\ldots$ & $\ldots$ & $\ldots$ & $\ldots$ \\
$n$ & $L$ & L.r & L + L.r & 0 \\
\hline Total & L & n. L.r & n. L.r $+L$ & - \\
\hline
\end{tabular}

\section{Partial Repayment Plan or Balloon Repayment Plan}

In this case, instead of avoiding payment of principal up to maturity of loan, farmer repays the part of principal amount over the years. This plan assumes that the enterprise financed will be able to generate a large amount at the end of repayment period compared to the rest of period. For this reason, a large portion of principal is set aside for repayment in the last year of repayment period.

Let's assume that a farmer borrows a loan amount $L$ at the rate of $r$ percent per annum for $N=n+$ 1 years. So, he decides to repay $\delta$ amount each during first $n$ years towards the principal in addition to regular interest and in the $\mathrm{N}^{\text {th }}$ year he will repay the remaining loan amount all together. Let the remaining amount be called Last_year_due. This Last_year_due amount is upon the wish of farmer-borrower but subject to constraint that $L>$ Last_year_due $>0$. Let $\delta=\frac{L-\text { Last_year_due }_{-}}{n}$. Let $m$ be a number such that $m>n \& m=L / \delta$. Here, $m$ can be defined as the term of period, when for all years in the repayment term, principal component becomes $\delta$ per annum. Now we can write formula for Last_year_due as $L-n \delta$. The $m$ can be defined

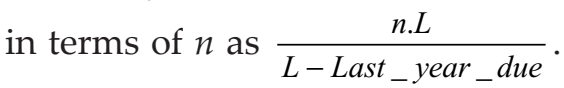

Table 2: Loan Repayment schedule under Partial Repayment Plan

\begin{tabular}{|c|c|c|c|c|}
\hline Year & $\begin{array}{l}\text { Prin- } \\
\text { cipal }\end{array}$ & Interest & $\begin{array}{c}\text { Instal- } \\
\text { ment }\end{array}$ & $\begin{array}{c}\text { Bal- } \\
\text { ance }\end{array}$ \\
\hline 1 & $\delta$ & L.r & $\delta+L . r$ & $L-\delta$ \\
\hline 2 & $\delta$ & $(L-\delta) \cdot r$ & $\delta+(L-\delta) \cdot r$ & $L-2 . \delta$ \\
\hline 3 & $\delta$ & $(L-2 . \delta) . r$ & $\delta+(L-2 . \delta) \cdot r$ & $L-3 . \delta$ \\
\hline$\ldots$ & $\ldots$ & $\ldots$ & $\ldots$ & $\ldots$ \\
\hline$n$ & $\delta$ & $\{L-(n-1) . \delta\} . r$ & $\delta+\{L-(n-1) \cdot \delta\} . r$ & $L-n . \delta$ \\
\hline$n+1$ & $L-n \delta$ & $\{L-n . \delta\} . r$ & $(L-n \delta) \cdot(1+r)$ & 0 \\
\hline \multirow{2}{*}{ Total } & \multirow{2}{*}{$L$} & $(n+1) \cdot r \cdot L \cdot(2 \cdot m-n)$ & $(n+1) \cdot r \cdot L \cdot(2 \cdot m-n)$ & - \\
\hline & & $2 . m$ & $2 . m$ & \\
\hline
\end{tabular}

\section{Amortized Repayment Plan}

Amortization means gradual repayment or writing off of an original amount. Like Partial repayment plan, here also entire loan is repaid in series of instalments which technically speaking is amortization of loan amount. However, method of calculating the instalment differs from the former. Amortization plans are of two types, viz., amortized decreasing repayment plan and amortized even repayment plan.

\subsection{Amortized Decreasing Repayment Plan:} This plan is basically an extension of Partial repayment plan and this will be demonstrated mathematically in later part of this section. The 
principal component has been equally spread across all years in repayment schedule. The interest component decreases as the outstanding amount decreases with every passing year. This leads to falling instalment amount over the entire repayment schedule. Let's assume that a farmer borrows a loan amount $L$ at the rate of $r$ percent per annum for $n$ years. So, the fixed principal component to be paid every year would be $\delta=\frac{L}{n}$.

Table 3: Loan Repayment schedule under Amortized Decreasing Repayment Plan

\begin{tabular}{ccccc}
\hline Year & Principal & Interest & Instalment & Balance \\
1 & $\delta$ & $L . r$ & $\delta+L . r$ & $L-\delta$ \\
2 & $\delta$ & $(L-\delta) . r$ & $\delta+(L-\delta) . r$ & $L-2 . \delta$ \\
3 & $\delta$ & $(L-2 . \delta) . r$ & $\delta+(L-2 . \delta) . r$ & $L-3 . \delta$ \\
$\ldots$ & $\ldots$ & $\ldots$ & $\ldots$ & $\ldots$ \\
$n$ & $\delta$ & $\{L-(n-1) . \delta\} . r$ & $\delta+\{L-(n-1) \cdot \delta\} . r$ & $L-n . \delta=0$ \\
\hline Total & $n . \delta=L$ & $\frac{r . L(n+1)}{2}$ & $L+\frac{r \cdot L(n+1)}{2}$ & - \\
\hline
\end{tabular}

3.2. Amortized Even Repayment Plan: In this plan, instalment amount is kept constant over entire repayment schedule and for this reason it is called equated annual instalment method. The interest component is arrived at by calculating interest on principal amount outstanding in previous period and principal component of this instalment is arrived at by deducing the interest component from instalment. Let's assume that the banker fixes the instalment to be $I$ amount per annum for a loan of
$L$ amount rented at the rate of $r$ per cent per annum to be repaid back in years.

Here, formula for calculation of instalment amount can be derived as following:

Since balance at the end of the $n^{\text {th }}$ year must be zero and hence we take the expression for balance at the end of the $n^{\text {th }}$ year.

$$
\begin{array}{ll}
L .(1+r)^{n}-I \cdot\left\{\frac{(1+r)^{n}-1}{r}\right\}=0 & \Rightarrow L \cdot(1+r)^{n}=I \cdot\left\{\frac{(1+r)^{n}-1}{r}\right\} \\
\begin{array}{cl}
\Rightarrow L .(1+r)^{n} \cdot r=I \cdot\left\{(1+r)^{n}-1\right\} & \Rightarrow \frac{L \cdot(1+r)^{n} \cdot r}{\left\{(1+r)^{n}-1\right\}}=I \Rightarrow \frac{L . r}{\left\{1-(1+r)^{-n}\right\}} \\
=I &
\end{array}
\end{array}
$$

\section{(B) Convergence and Cost comparisons among Various Repayment Plans}

\section{Amortized Decreasing and Partial Repayment Plan}

It is interesting to note that in case of partial repayment plan, as the value of $m \rightarrow N$ the partial repayment plan approaches to amortized decreasing repayment plan. At the last when $m=N$ then partial repayment plan becomes amortized decreasing repayment plan. In this extreme case, Last_year_due= $L / N$. Mathematically, for interest component, it can be represented as following:

$$
\lim _{m \rightarrow N} \frac{N \cdot r \cdot L \cdot(2 \cdot m-N+1)}{2 \cdot m}=\frac{r \cdot L \cdot N}{2}
$$

\begin{tabular}{|c|c|c|c|c|}
\hline Year & Instalment & Interest & Principal & Balance \\
\hline 1 & $I$ & L.r & $I-L . r$ & $L-I+L . r=L .(1+r)-I$ \\
\hline 2 & $I$ & L. $(1+r) . r-I . r$ & $I .(1+r)-L .(1+r) . r$ & $L .(1+r)^{2}-I .(2+r)$ \\
\hline 3 & $I$ & $L .(1+r)^{2} . r-I .(2+r) . r$ & $I .(1+r)^{2}-L .(1+r)^{2} . r$ & $L .(1+r)^{3}-I .\left(3+3 \cdot r+r^{2}\right)$ \\
\hline 4 & $I$ & $L .(1+r)^{3} \cdot r-I .\left(3+3 . r+r^{2}\right) \cdot r$ & $I .(1+r)^{3}-L \cdot(1+r)^{3} . r$ & $L .(1+r)^{4}-I .\left(4+6 . r+4 . r^{2}+r^{3}\right)$ \\
\hline$\cdots$ & ... & $\cdots$ & $\ldots$ & $\ldots$ \\
\hline$n$ & $I$ & $(L . r-I) \cdot(1+r)^{n-1}+I$ & $(I-L \cdot r) \cdot(1+r)^{n-1}$ & $L .(1+r)^{n}-I \cdot\left\{\frac{(1+r)^{n}-1}{r}\right\}$ \\
\hline Total & n.I & $\begin{array}{l}n . I+\left(\frac{L . r-I}{r}\right) \cdot\{(1+r) n-1\} \\
-n . I-L\end{array}$ & $\left\{(1+r)^{n}-1\right\} \cdot\left(\frac{I-L \cdot r}{r}=L\right.$ & n.I \\
\hline
\end{tabular}

Where $N$ is as defined earlier in Partial repayment plan.

Table 4: Loan Repayment schedule under Amortized Even Repayment Plan 


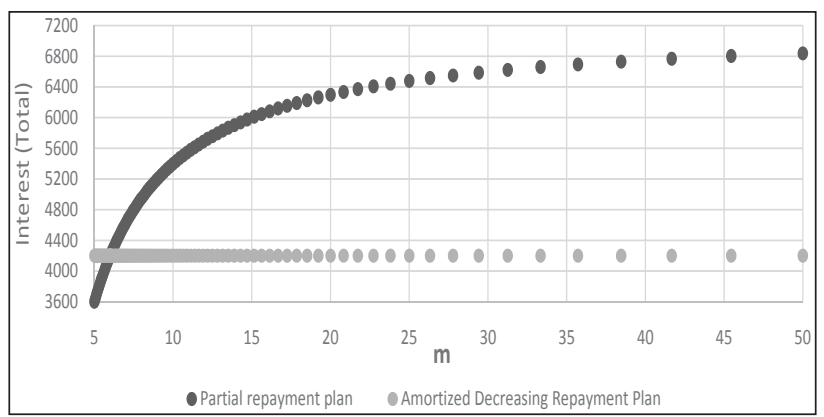

Fig. 1: Interest (Total) Vs. $m$ for Partial and Amortized Decreasing Repayment Plans

Fig. 1 shows that for $L=10000, r=0.12$ and $N=6$, then total interest for partial repayment plan equals to total interest for amortized decreasing repayment plan when $m=N$.

Now similarly comparing the balloon repayment plan with amortized decreasing repayment plan as following:

Total Interest paid in amortized decreasing repayment plan Total Interest paid in baloon repayment plan

$$
=\frac{(N+1) \cdot L \cdot r / 2}{N \cdot L \cdot r \cdot(2 m-N+1) / 2 m}
$$

which upon simplification leads to $\left(\frac{N+1}{N}\right)\left(\frac{m}{2 m-N+1}\right)$

This ratio upon substitution and simplification leads to $\left(\frac{N-1}{N}\right)\left\{\frac{1}{1+\frac{\text { Last_year_due }_{-}}{L}}\right\}$. This ratio ${ }^{1}$ is $<1$ for as long as Last_year_due $\geq \delta$, Amortized decreasing repayment plan works out to be cheaper than balloon repayment plan for farmers in long run for equal number of years in repayment schedule. This is also evident from Fig. 2.

It is interesting to note that, when, Last_year_due = 0 then $m=N-1$ and the mathematical expression for total instalment under Partial Repayment plan reduces to $L .\left(\frac{N . r}{2}+1\right)$. While the expression for total instalment under Amortized Decreasing Repayment Plan is $L .\left(\frac{(N+1) \cdot r}{2}+1\right)$. Now the difference between

${ }^{1}$ This ratio can alternatively be written as $\frac{N+1}{N+\frac{\text { Last_year_due }}{\delta}}$ where $\delta$

$=L / N$. This expression proves the statement that for Last_year_due $\geq \delta$, the Partial repayment plan remains a costlier than Amortized decreasing repayment plan. the two expressions is the reason why total instalment under Partial repayment plan lags that of under Amortized Decreasing repayment plan year- on-year. Table 5 illustrates the case discussed above for $L=100000, r=19 \%$ and Last_year_due $=0$.

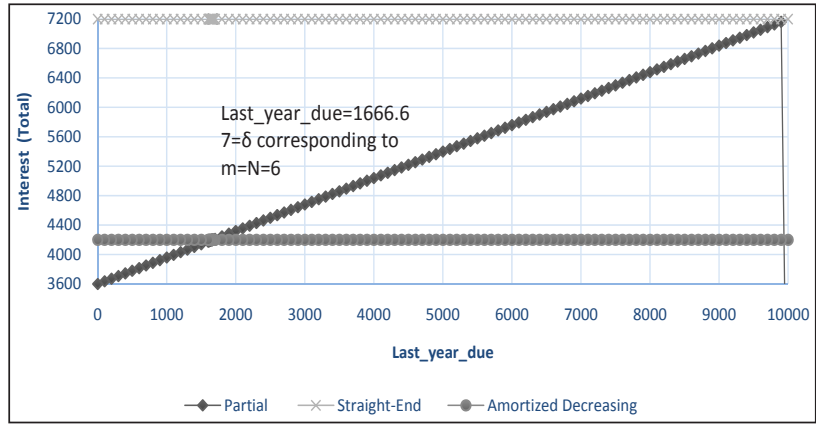

Fig. 2: Convergence of Interest (Total) component of Partial Repayment Plan towards Straight-End and Amortized Decreasing Repayment Plan

Table 5: An illustration of lead-lag relationship in total instalment for Partial and Amortized Decreasing Repayment Plan

\begin{tabular}{|c|c|c|c|}
\hline $\mathbf{N}$ & $\begin{array}{c}\text { Amortized Decreasing } \\
\text { Repayment Plan }\end{array}$ & $\begin{array}{c}\text { Partial } \\
\text { Repayment Plan }\end{array}$ & $\mathbf{m}$ \\
\hline 1 & 119000 & \#DIV/0!- & 0.00000 \\
\hline 2 & 128500 & 119000 & 1.00000 \\
\hline 3 & 138000 & 128500 & 2.00000 \\
\hline 4 & 147500 & 138000 & 3.00000 \\
\hline 5 & 157000 & 147500 & 4.00000 \\
\hline 6 & 166500 & $157000^{-}$ & 5.00000 \\
\hline 7 & 176000 & $166500-$ & 6.00000 \\
\hline 8 & 185500 & 176000 & 7.00000 \\
\hline 9 & 195000 & $185500^{-7}$ & 8.00000 \\
\hline 10 & 204500 & 195000 & $>9.00000$ \\
\hline 24 & 337500 & $328000^{-}$ & 23.00000 \\
\hline 25 & 347000 & 337500 & 24.00000 \\
\hline
\end{tabular}

Similar to the lead-lag relationship being examined above, it is equally interesting to note that when Last_year_due $=L / 2$, the direction of lead-lag relationship reverses, from earlier one being Amortized Decreasing Repayment Plan to Partial Repayment Plan to Partial Repayment Plan to Amortized Decreasing Repayment Plan. When Last_year_due $=L / 2$, then mathematical expression for instalment under Partial Repayment Plan reduces to L. $(0.75 N . r+1)$ and it is $L .\{0.5(N+1) . r+$ $1\}$ for Amortized Decreasing Repayment Plan. The series of lag period is an arithmetic progression with initial lag period being one and distance between successive lag periods equal to one. Table 6 illustrates this case. 
Table 6: An illustration of Reversal of lead-lag relationship in total installment for Partial and

Amortized Decreasing Repayment Plan

\begin{tabular}{|c|c|c|}
\hline $\mathbf{N}$ & $\begin{array}{c}\text { Amortized Decreasing } \\
\text { Repayment Plan }\end{array}$ & $\begin{array}{l}\text { Partial Repayment } \\
\text { Plan }\end{array}$ \\
\hline 1 & $L \cdot(1+r)$ & $L .(1+0.75 r)$ \\
\hline 2 & L. $(1+1.5 r) \leftarrow$ & $\rightarrow L .(1+1.5 r)$ \\
\hline 3 & L. $(1+2 r)$ & L. $(1+2.25 r)$ \\
\hline 4 & L. $(1+2.5 r)$ & $-L \cdot(1+3 r)$ \\
\hline 5 & L. $(1+3 r)$ & L. $(1+3.75 r)$ \\
\hline 6 & L. $(1+3.5 r)$ & L. $(1+4.5 r)$ \\
\hline 7 & L. $(1+4 r)$ & L. $(1+5.25 r)$ \\
\hline 8 & L. $(1+4.5 r) \longleftarrow$ & $-L .(1+6 r)$ \\
\hline 9 & L. $(1+5 r)$ & L. $(1+6.75 r)$ \\
\hline 10 & L. $(1+5.5 r)$ & $\rightarrow L .(1+7.5 r)$ \\
\hline 11 & L. $(1+6 r) \leftarrow$ & $L .(1+8.25 r)$ \\
\hline 12 & L. $(1+6.5 r)$ & $\rightarrow L \cdot(1+9 r)$ \\
\hline 13 & L. $(1+7 r)$ & L. $(1+9.75 r)$ \\
\hline 14 & L. $(1+7.5 r)$ & L. $(1+10.5 r)$ \\
\hline 15 & L. $(1+8 r)$ & L. $(1+11.25 r)$ \\
\hline 16 & L. $(1+8.5 r)$ & L. $(1+12 r)$ \\
\hline 17 & L. $(1+9 r)$ & L. $(1+12.75 r)$ \\
\hline
\end{tabular}

Note: The curly bracket shows lag period length and the arrow line shows the lag.

\section{Straight-End and Partial Repayment Plan}

Analogous to previous case, if $m$ tends to infinity then partial repayment plan approaches StraightEnd Repayment Plan because as, $m \rightarrow \infty, \delta \rightarrow$ $0[m=L / \delta ; L \neq 0$. This makes Last_year_due $=L$ because $\delta$ has been defined as $L$ - Last_year_due/n. Now, convergence of interest component of Partial repayment plan to Straight-End repayment plan can be shown as following:

$$
\lim _{m \rightarrow \infty} \frac{N \cdot r \cdot L \cdot(2 \cdot m-N+1)}{2 \cdot m}=N \cdot L \cdot r
$$

Fig. 2 illustrates the above case wherein as Last_ year_due approaches then interest (Total) for partial repayment plan also approaches interest (Total) for straight-end repayment plan. Thus, from above explanations, about range of $m$, it can be inferred that $N-1 \leq m \leq \infty$ with lower extremum being achieved with Last_year_due $=0$ and higher extremum being achieved with Last_year_due $=L$.

Since, principal paid is same in both cases, hence only interest component needs to be compared to see which one is cost-effective.

Total Interest paid in Straight end repayment plan

Total Interest paid in baloon repayment plan

$$
=\frac{N \cdot L \cdot r}{N \cdot L \cdot r \cdot(2 m-N+1) / 2 m}
$$

This ratio can be simplified as $\frac{2 m}{(2 m-N+1)}$. In this ratio,after substitution of expression for from Partial repayment plan and simplifying terms leads to $\left\{\frac{2}{1+\frac{\text { Last_year_due }}{L}}\right\}$. Now this ratio can have two extreme values for the extreme values of parameter Last_year_due: for Last_year_due $=0$, this ratio equals two while for Last_year_due $=L$, this ratio equals one. Thus, for for $L>$ Last_year_due $>0$, the ratio has values less than one ${ }^{2}$.

Hence, it can be concluded that for equal number of years if farmer serves loan amount under two different repayment plans under comparison then balloon repayment plan stands to be cheaper to farmer.

\section{Amortized Even and Partial Repayment Plan}

To compare the Amortized Even repayment plan with Partial repayment plan, we solve the ratio of instalments of two plans as following:

Total installment paid in amortized even repayment plan

Total installment paid in Partial repayment plan $=\frac{N \cdot L \cdot r /\left\{1-(1+r)^{-N}\right\}}{L+\frac{N \cdot r \cdot L \cdot(2 m-N+1)}{2 m}}$

This ratio simplifies to,

$\left\{\frac{1}{1-(1+r)^{-N}}\right\}\left(\frac{1}{\frac{1}{N . r}+\left(\frac{1}{2}+\frac{\text { Last_year_due }}{2 . L}\right)}\right)$

Now applying limits to find limiting value of this ratio as following:

$\lim _{N \rightarrow \infty}\left\{\frac{1}{1-(1+r)^{-N}}\right\}\left(\frac{1}{\frac{1}{N . r}+\left(\frac{1}{2}+\frac{\text { Last_year_due }}{2 . L}\right)}\right)=\frac{1}{\left(\frac{1}{2}+\frac{\text { Last_year_due }}{2 \cdot L_{2}}\right)}$

\footnotetext{
${ }^{2}$ We are excluding the case of Last_year_due $=0$ because only admissible value according to convergence possibility is Last_year_due $=L$ not the former one.
} 
Now the value of this ratio solely depends on Last_year_due as following:

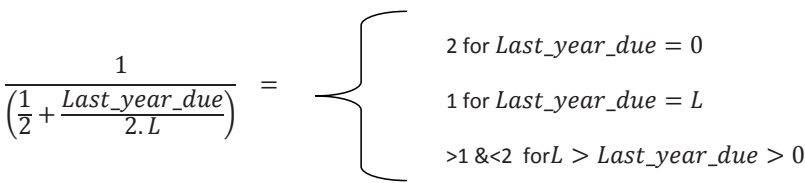

Thus, it can be inferred that for $n \rightarrow \infty$ and Last_ year_due $=L$, instalment component of both the plans converges. This convergence shall as well happen for interest component as well. This result also tells that Amortized Even repayment plan will be costlier than Partial repayment plan for every year increase in repayment schedule. The result achieved on finding limiting value of ratio for $r \rightarrow$ $\infty$ will be same as that of $n \rightarrow \infty$. This implies that for any term of repayment, a sufficient increase in rate of interest will make no difference in cost involved with either plan used if Last yeardue $)=0$, else Amortized even repayment plan will cost more to borrower than Partial repayment plan.

\section{Amortized Decreasing and Even Repayment Plan}

Similarly, comparison is taken up between amortized even repayment and amortized decreasing repayment plan as following:

Total installment paid in amortized even repayment plan

Total installment paid in amortized decreasing repayment plan $=\frac{n L r /\left\{1-(1+r)^{-n}\right\}}{L(n r+1) / 2}$

Upon simplification of this ratio yields,

$\frac{2 L n r}{L(1+n r)\left\{1-(1+r)^{-n}\right\}}=\left\{\frac{2}{1-(1+r)^{-n}}\right\}\left(1+\frac{1}{n r}\right)$

To find the limiting value of the above ratio, we use concept of limits as following:

$\lim _{n \rightarrow \infty}\left\{\frac{2}{1-(1+r)^{-n}}\right\}\left(1+\frac{1}{n r}\right)=2$

This result implies that as number of years in repayment schedule increases the Amortized Even repayment plan works out to be costlier than Amortized Decreasing repayment plan, irrespective of rate of interest. For $r \rightarrow \infty$, the above ratio will approach a limiting value of two as well which means that irrespective of number of years in repayment schedule, Amortized even repayment plan will cost more than Amortized decreasing repayment plan.

\section{Straight-End and Amortized Even Repayment Plan}

To compare the Amortized Even repayment plan with straight end repayment plan, we solve ratio of instalments of two plans as following:

Total installment paid in amortized even repayment plan Total installment paid in Straight - End repayment plan $=\frac{n L r /\left\{1-(1+r)^{-n}\right\}}{L(n r+1)}$

This ratio simplifies to,

$$
\left\{\frac{1}{1-(1+r)^{-n}}\right\}\left(1+\frac{1}{n r}\right)
$$

and from previous case, it is obvious that the limiting value of this ratio works out to be one. Thus, as $n \rightarrow \infty$, instalment component in both plans converge. This ratio will also approach one for $r \rightarrow \infty$.

It is also interesting to note that, as $n \rightarrow \infty$, annual instalment under Amortized Even repayment plan converges to interest component annual and annual instalment for first $n-1$ years. This can be shown mathematically as following:

$\lim _{n \rightarrow \infty} \operatorname{L.r} /\left\{1-(1+r)^{-n}\right\}=L . r$

\section{Amortized Decreasing and Straight-End Repayment Plan}

To compare these two plans, first their interest components are compared as following:

Total Interest paid in Straight end repayment plan

Total Interest paid in Amortized decreasing repayment plan $=\frac{n \cdot L \cdot r}{(n+1) \cdot L \cdot r / 2}$

This ratio upon simplification reduces to $2 . n / 1+n$ the value of which approaches two as $n \rightarrow \infty$. For $n=1$, this ratio has value of one. Thus as number of years in repayment plan increases, Straight-End repayment plan goes on to become more and more costly and in extreme case it will cost double the interest paid in Amortized Decreasing Repayment Plan, regardless of interest rate charged. To shed more light on the costs involved in these two plans, comparison of total instalment component is taken up as shown below:

Total installment paid in Amortized Decreasing repayment plan

Total installment paid in Straight - End repayment plan $=\frac{L+\{(n+1) \cdot r \cdot L / 2\}}{L(n r+1)}$ 
This ratio upon simplification reduces to $\frac{1}{2}\left(1+\frac{1+r}{1+n \cdot r}\right)$ . For $n \rightarrow \infty$, this ratio approaches 0.5 irrespective of rate of interest involved. This means as number of years in repayment plan increase, Amortized decreasing repayment plan tends to be cheaper irrespective of rate of interest involved. For $r \rightarrow \infty$, this ratio becomes $\frac{1}{2}\left(1+\frac{1}{1+n}\right)$. This implies that as rate of interest increases, Straight-End repayment plan becomes costlier than Amortized decreasing repayment plan, irrespective of term of repayment.

The lead-lag relationship observed in section 3.1 is also evident in this case: total instalment under Straight -End Repayment Plan for $n$ number of years in repayment appears under Amortized Decreasing Repayment Plan with lag period of $n-1$ years. Table 7 illustrates this case. From Table 6A, it can be observed that lag period for is $n=\{2,3,4,5\}$ is $\{1,2,3,4\}$, respectively. The series of lag period is an arithmetic progression with initial lag period being one and distance between successive lag periods equal to one.
Table 6A: An illustration of lead-lag relationship in total instalment for Straight-End and Amortized Decreasing Repayment Plans

\begin{tabular}{|c|c|c|}
\hline$n$ & $\begin{array}{l}\text { Amortized Decreasing } \\
\text { Repayment Plan }\end{array}$ & $\begin{array}{l}\text { Straight-End } \\
\text { Repayment Plan }\end{array}$ \\
\hline 1 & L. $(1+r)$ & L. $(1+r)$ \\
\hline 2 & L. $(1+1.5 r)$ & $L .(1+2 r)$ \\
\hline 3 & L. $(1+2 r)$ & $-L \cdot(1+3 r)$ \\
\hline 4 & L. $(1+2.5 r)$ & $-L .(1+4 r)$ \\
\hline 5 & L. $(1+3 r)$ & L. $(1+5 r)$ \\
\hline 6 & L. $(1+3.5 r)$ & L. $(1+6 r)$ \\
\hline 7 & L. $(1+4 r) \longleftarrow$ & L. $(1+7 r)$ \\
\hline 8 & L. $(1+4.5 r)$ & L. $(1+8 r)$ \\
\hline 9 & L. $(1+5 r)$ & L. $(1+9 r)$ \\
\hline 10 & L. $(1+5.5 r)$ & L. $(1+10 r)$ \\
\hline
\end{tabular}

Note: The curly bracket shows lag period length and the arrow line shows the lag.

\section{CONCLUSION}

This paper has derived generalized expression for various repayment plans which not only have its utility in banking and academics It also serves attract attention from mathematically oriented Economist who will study the these plans further with greater interest and will come out with better suggestions to improve farming community. A

Table 7: Summary of Convergence among Repayment Plans

\begin{tabular}{lccll}
\hline & Straight-End & Partial & Amortized Decreasing & Amortized Even \\
\hline $\begin{array}{l}\text { Partial/Balloon } \\
\text { (Interest Component) }\end{array}$ & $\begin{array}{l}m \rightarrow \infty \text { or } \\
\text { Last_year_due } \\
=L\end{array}$ & - & $\begin{array}{l}m \rightarrow N \text { or } \\
\text { Last_year_due }=L / N\end{array}$ & $\begin{array}{l}\text { Last_year_due }=L \\
\text { Last_o \& }\end{array}$ \\
$\begin{array}{l}\text { Amortized Decreasing } \\
\text { (Interest Component) }\end{array}$ & - & - & & $\begin{array}{l}n \rightarrow \infty \text { with cofactor } \\
\text { of } 2^{*}\end{array}$ \\
$\begin{array}{l}\text { Amortized Even } \\
\text { Instalment Component) }\end{array}$ & $n \rightarrow \infty$ & - & $n \rightarrow \infty \&$ cofactor of 0.5 & \\
\hline
\end{tabular}

Table 8: Summary of Cost Comparison among Repayment Plans

\begin{tabular}{lcccc}
\hline & $\begin{array}{c}\text { Straight- } \\
\text { End }\end{array}$ & Partial & $\begin{array}{c}\text { Amortized } \\
\text { Decreasing }\end{array}$ & Amortized Even \\
\hline Partial/Balloon & Less & - & $\begin{array}{c}\text { Less with } \\
\text { Last_year_due }<\delta\end{array}$ & $\begin{array}{c}\text { Depends on value of } \\
N, r \text { \& }\left(\frac{\text { Last_year_due }}{L}\right)\end{array}$ \\
$\begin{array}{l}\text { Amortized } \\
\text { Decreasing }\end{array}$ & Less & $\begin{array}{c}\text { Less with } \\
\text { Less }\end{array}$ \\
$\begin{array}{l}\text { Amortized } \\
\text { Even }\end{array}$ & Less & $\begin{array}{c}\text { Depends on value of } \\
N, r \&\left(\frac{\text { Last_year_due }}{L}\right)\end{array}$ & More & \\
\hline
\end{tabular}


summary of the results of convergence and costcomparison among various repayment plans has been provided in Table $7 \& 8$.

\section{REFERENCES}

Duisenberg, W.F. 2001. The role of financial markets for economic growth. BIS Review No. 48.

Mayer, Colin. 1990. "Financial systems, corporate finance, and economic development." In Asymmetric information, corporate finance, and investment, pp. 307-332. University of Chicago Press.

Reddy, S.S., Ram, P.R., Sastry, T.V.N. and Devi. I.B. 2004. "Agriculture Economics".
R Core Team. R: A language and environment for statistical computing. R Foundation for Statistical Computing, Vienna, Austria, 2017. URL https://www.R-project.org/.

Thomas, J. Hoffmann, Nan, M. Laird. 2009. fgui: A Method for Automatically Creating Graphical User Interfaces for Command-Line R Packages. Journal of Statistical Software, 30(2): 1-14, 2009.

Wikipedia contributors. Geometric progression. In Wikipedia, The Free Encyclopedia. Retrieved 06:15, October 20, 2018, from https://en.wikipedia.org/w/index.php?title = Geometric_progression\&oldid=863951355 